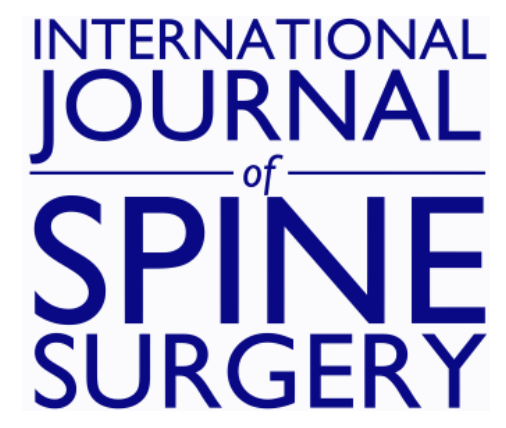

\title{
Role of posterior elements in the disc bulging of a degenerated cervical spine
}

Farid Amirouche, Giovanni F. Solitro, Kris Siemionow, David Drucker, Ashish Upadhyay and Priyesh Patel

Int J Spine Surg 2015, 9 ()

doi: https://doi.org/10.14444/2013

http://ijssurgery.com/content/9/13

This information is current as of April 26, 2023.

Email Alerts Receive free email-alerts when new articles cite this article. Sign up at:

http://ijssurgery.com/alerts

The International Journal of Shing Surgerih 2397 Waterbury Circle, Suite 1,

Aurora, IL 60504, Phone: +1-630-375-1432 


\section{Role of posterior elements in the disc bulging of a degenerated cervical spine.}

Farid Amirouche, PhD, Giovanni F. Solitro, PhD, Kris Siemionow MD, David Drucker MS, Ashish Upadhyay MD, Priyesh Patel BS

Department of Orthopaedics, College of Medicine, University of Illinois at Chicago, Chicago, IL, USA

\section{Abstract}

Background

Many studies have been developed to characterize the mechanical behavior of the intervertebral disc specifically for the lumbar spine and there have been limited studies done on the cervical spine with the goal to evaluate the strength of the cervical spine under compression without any information on the bulging of the intervertebral discs. The goal of the current study is to examine the deformation response of the cervical intervertebral disc classified with grade III or greater degeneration and analyze the relationship between axial deformation and anterior and posterior bulge under compression up to $550 \mathrm{~N}$.

Methods

Each specimen was compressed for 3 cycles to a maximum load of $550 \mathrm{~N}$ in steps of $50 \mathrm{~N}$. The bulge was measured using Linear Variable Differential Transformers (LVDTs on an intact spinal segment, spinal segment with post laminectomy, and spinal segment post facetectomy.

Results

The anterior budge for an intact spinal segment shows a change of slope at loads of $262 \mathrm{~N} \pm 66 \mathrm{~N}$. For a physiological load of $250 \mathrm{~N}$ the vertical displacement or spine segment height was reduced by $10.1 \%$ for an intact segment and 8.78\% for the laminectomy and facetectomy configurations with $\mathrm{F}=0.159\left(\mathrm{~F}_{\text {crit }}=3.89\right)$ with no statistical difference observed. For the post laminectomy there was a decrease of 35\% in anterior bulge compared to the intact specimen.

\section{Conclusions}

Our results show that for grade III disc degeneration the cervical segments bulging for both the laminectomy and facetectomy procedures are not significantly different. In post laminectomy the average anterior and posterior bulges are similar to the average anterior and posterior bulge post facetectomy.

KEYWORDS: DISC DEGENERATION, CERVICAL SPINE, BULGING, LAMINECTOMY, FACETECTOMY

VOLUME 9 ARTICLE 13 DOI: 10.14444/2013

\section{Introduction}

The cervical spine is subject to many ailments.

Radiculopathies, myelopathies, and many other disorders are often related to intervertebral disc (IVD) diseases. Neck and upper back pain affects mainly women, has a mean point prevalence of $14.4 \%$, an estimated lifetime prevalence up to $5.6 \%$ in $\mathrm{US}^{1}$ and is mainly due to IVD degeneration. Intervertebral disc degeneration is a natural occurrence related to age. ${ }^{2}$ By the age of $70-80$, there is a $100 \%$ prevalence of individuals with degenerative disc disease. ${ }^{3}$ Protrusions and prolapses can place pressure on the spinal cord or nerve roots and cause symptoms. Procedures such as laminectomies and facetectomies are done in an attempt to relieve the associated symptoms. These procedures are often performed on patients with various levels of disc degeneration. Gerard et al. ${ }^{4}$ reported, for patients with myelopathy from cervical stenosis, clinical improvement in $62.5 \%$ to $83 \%$ of cases adopting posterior decompression with either laminectomy or laminoplasty. Though outcomes are usually beneficial, these procedures alter the forces on the intervertebral discs, many of which are still not completely understood. IVD degeneration can be measured by the grading system of Pfirrmann et al. ${ }^{5}$ that provides a semi-quantitative evaluation of disc degeneration. Procedures such as facetectomies also give rise to questions such as stability of the spine. There is a general agreement that total removal of 
the facet produces an unstable situation. Due to the high prevalence of degenerative disc disease and the decrease in spinal stability after these operations it is important to study the effects of these procedures on the IVD. ${ }^{3,6}$

Many studies have been developed to characterize the mechanical behavior of the intervertebral disc specifically for the lumbar spine, since in 1974, Keith Markolf completed a study in which 24 Functional Spinal Units (FSUs) without posterior elements were compressed to $1000 \mathrm{~N}$ which resulted in a vertical deformation of $0.7 \mathrm{~mm} .{ }^{7}$ In 1978, a study done by J.S. Shah in which six specimens with two discs and three vertebral body segments were compressed used transducers to measure the bulge of the IVD when compressed to $490 \mathrm{~N}$ and $981 \mathrm{~N}$ and the amount of bulge was $0.4 \mathrm{~mm}$ and $0.6 \mathrm{~mm}$ respectively. ${ }^{8} \mathrm{~A}$ third lumbar study by Karl Wenger in 1997 took 16 FSU and compressed them from $100 \mathrm{~N}$ to $2500 \mathrm{~N}$. The specimens were then measured for amount of bulge by imaging the specimen before loading and at maximum loading: the mean anterior bulge was found to be $0.37 \mathrm{~mm} \pm 0.27 \mathrm{~mm}$ and range $0.07-0.91 \mathrm{~mm}$. It was found to have a mean lateral bulge of $0.65 \mathrm{~mm} \pm 0.42$ and range $0.09-1.29 \mathrm{~mm} .{ }^{9}$ More recently advanced techniques to estimate disc bulging have been proposed. ${ }^{10-12}$ Heuer et al. ${ }^{12}$ used an effective laser scanning technique which provided some interesting results. The bulging of the cadaveric specimens tested ranged from $0.70 \mathrm{~mm}$ to $0.87 \mathrm{~mm}$ with a resolution of $25 \mu \mathrm{m}$ under a compression of $500 \mathrm{~N}$. In contrast there have been limited studies done on the cervical spine with the goal to evaluate the strength of the cervical spine under compression and bending without any information on the bulging of the intervertebral discs. Moroney ${ }^{13}$ completed a study in which 35 cervical segments were tested and has found a compressional stiffness of $1317 \mathrm{~N} / \mathrm{mm}$, reduced by the dissection of the posterior elements in $492 \mathrm{~N} / \mathrm{mm}$. $\mathrm{M}$. Shea ${ }^{14}$ on cervical spinal units specimens composed by two discs and three vertebral body segments with the posterior elements retained, has found at $300 \mathrm{~N}$ in compression a vertical displacement of $4.7 \mathrm{~mm}$ at the failure load of $2158 \mathrm{~N} \pm 1055 \mathrm{~N}$. In another study by Przybyla ${ }^{15}$ in 2007, 22 cervical FSU were secured in aluminum cup with plaster and were compressed until failure found at $2400 \mathrm{~N} \pm 960 \mathrm{~N}$ and characterized by an elastic limit of $1230 \mathrm{~N}$ $\pm 460 \mathrm{~N}$. Compared to previous studies, our current study takes both variables, vertical deformation and IVD bulge, into account and examined how an axial load on a cervical spinal segment, characterized with grade III or greater disc degeneration on the Pfirrmann grading system is associated with intervertebral disc bulge with posterior elements intact, after laminectomy, and after facetectomy. This study presents additional understanding of the properties and characteristics of the human cervical IVD. Results from this study can be used, for the level of degeneration considered, to evaluate the contribution of the residual IVD bulge in narrowing the intervertebral foramina provide insight for surgical procedures or the development of artificial discs, and help improve therapies for neck related injuries.

\section{Materials and Methods}

\section{Specimen preparation}

Five intact cervical spines obtained from subjects with age of $54 \pm 9$ were sectioned into two FSUs: C3-C4 and C5-C6. The FSUs were cleaned of muscles and tendons but the IVDs and associated ligaments were left intact. The specimens were dissected such that a smooth level surface was prepared on the superior and inferior sides of the FSU to allow for symmetric and uniform load distribution. The specimens were stored frozen at $-20^{\circ} \mathrm{C}$ and were thawed slowly in a refrigerator for 24 hours before testing. Each segment was prepared in three configurations according to the three consecutive phases of testing: in the first configuration, the FSUs were left intact (Figure 1a), the second configuration was obtained for dissection of the spinous process, simulating the laminectomy, (Figure 1b) than for sequential dissection was obtained the third configuration characterizing the facetectomy (Figure 1c).

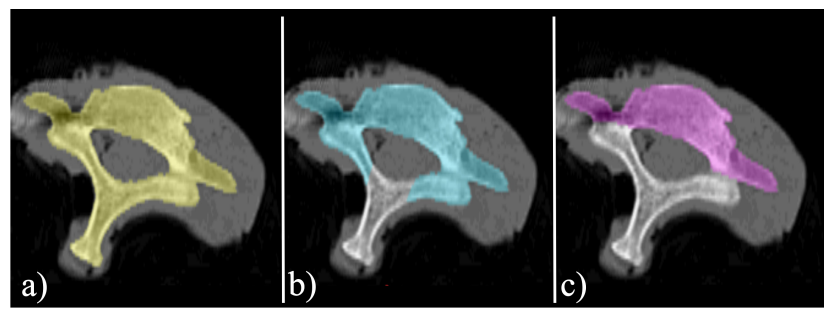

Fig. 1. Three configurations adopted for each specimen: a) intact segment, b) laminectomy and c) facetectomy.

Downloaded from http://ijssurgery.com/ by guest on April 26, 2023 


\section{Biomechanical testing}

The specimens were placed, unconstrained, into an Instron electromechanical tensile-testing Machine 5569 (Instron, Norwood, MA). A preload of $50 \mathrm{~N}$ was applied before testing to ensure full contact and to minimize slippage of the specimen. Each specimen was compressed in the machine for 3 cycles for each maximum load. The maximum axial compressive load increased in the vertical direction from 100 $\mathrm{N}$ to $550 \mathrm{~N}$, safe value imposed equivalent to the $45 \%$ of the elastic limit load found at $1230 \mathrm{~N} \pm 460 \mathrm{~N}$ by Przybyla. ${ }^{15}$ All tests were conducted in steps of $50 \mathrm{~N}$ at a rate of $1 \mathrm{~mm} / \mathrm{min}$. The change in vertical deformation was measured using the values provided by the Instron machine at a frequency of $50 \mathrm{~Hz}$ and the repeatability across cycles between $\pm 10 \%$ was assumed has indication of non-damaged specimen. The bulge was then measured using Linear Variable Differential Transformers (LVDTs) series 330 miniature AC (Trans-Tek, Inc. Ellington, CT) with accuracy of $+/-0.25 \%$ and nonlinearity less than $0.2 \%$ of full scale (Figure 2).

For the first configuration, both LVDTs were placed in the anterior-posterior direction, on the segment C3-C4 one sensor was pointed on the posterior process measuring the rigid displacement of the segment (Figure 3) while the second sensor was measuring the anterior disc bulging, on the bigger segments C5-C6 the two sensors were both placed anteriorly were the rigid motion was evaluated trough the sensor on the vertebral body.

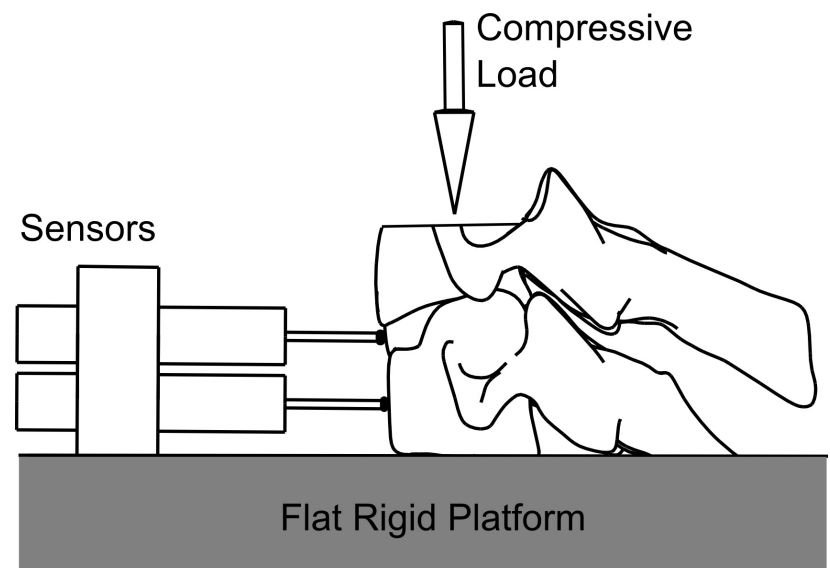

Fig. 2. Diagram of Deformation and Load Directions. There was an axial load applied to the specimen the deformation was measured in the vertical and anterior directions.
In the other two configurations, associated to the laminectomy and the facetectomy, where the posterior wall of the vertebral body was accessible an additional sensor, also with posterior-anterior direction was added to measure the posterior bulge (Figure 4).

After the testing of all the specimens The FSUs were then sectioned along the sagittal plane (Figure 5) for gross analysis of the IVD in order to characterize the type or extent of failure if any. Gross histological analysis of the cadaver spinal units was done to observe tissue properties specific to specimens used. The Pfirrmann grading scale was used to determine the grade of disc degeneration in the spinal units. Specimens with grade III or greater degeneration were used.

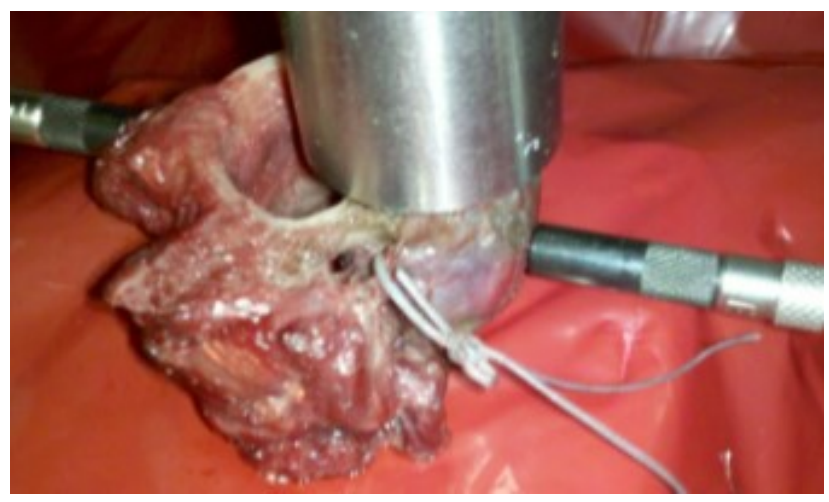

Fig. 3. Experimental Set-up for Intact Cervical Spine. The anterior sensor measures anterior bulge, the posterior sensor tracks the displacement of the bone movement.

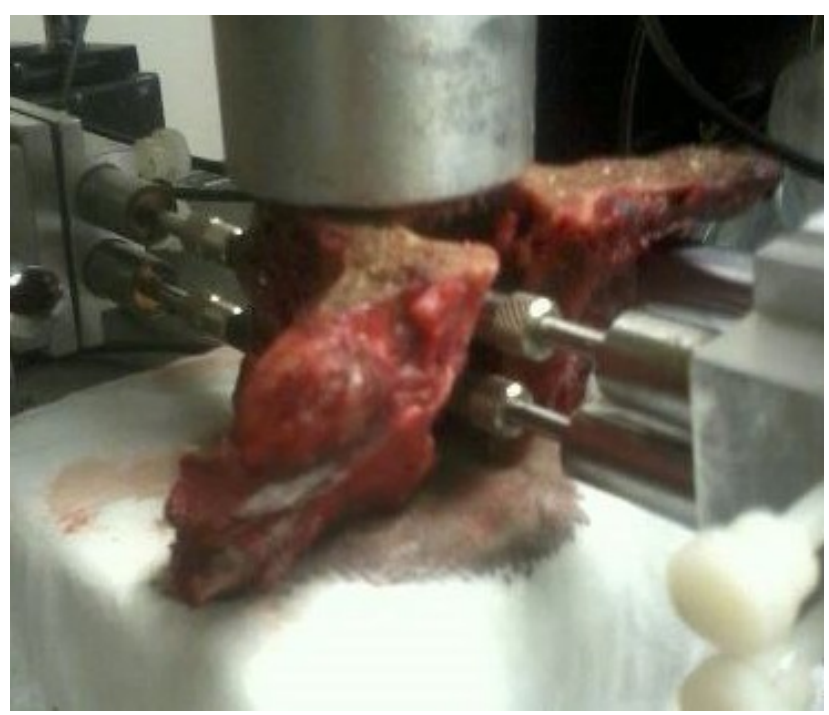

Fig. 4. Experimental Set-up for Cervical Spine Post Laminectomy, the additional sensor is added to measure the posterior bulge. 
Each tested sample was characterized by an estimated axial elasticity EIVD defined as:

$$
E_{I V D}=\frac{\text { Load }}{C S A} \frac{H_{0}}{\left(H_{0}-H\right)}
$$

The load-deformation ratio was based on the slope of the initial linear portion of the load deformation curve in the axial direction. The reference disc height $\mathrm{H}_{0}$ was measured in the middle of the obtained sagittal section using a digital caliper Mitutoyo 500 series (Mitutoyo America Corp. Aurora, Il) with an accuracy of $0.02 \mathrm{~mm}$. The flattened surface of the superior vertebral body was digitized and scaled to the sagittal and transversal width dimensions taken with the digital caliper. The Cross section area (CSA) was calculated as the area of the NURBS surface created on the digitized profile using Rhinoceros 3D (Robert McNeel \& Associates, Seattle, WA).

\section{Results}

The vertebral bodies of the C5-C6 specimens had average sagittal dimension of $16.5 \mathrm{~mm} \pm 2.1 \mathrm{~mm}$ and coronal of $26.25 \mathrm{~mm} \pm 1.8 \mathrm{~mm}$ and they were bigger than the specimens C3-C4 characterized by sagittal thickness of $14.1 \mathrm{~mm} \pm 1.9 \mathrm{~mm}$ and a coronal width of $21.7 \mathrm{~mm} \pm 3.2 \mathrm{~mm}$. The average cross sectional area (CSA) of all the specimens was found to be 296.25 $\mathrm{mm}^{2} \pm 49.8 \mathrm{~mm}^{2}$ with a range of $240 \mathrm{~mm}^{2}$ to 373 $\mathrm{mm}^{2}$. Dimensional measurements match with literature. ${ }^{16}$ Histological examination showed cervical spinal segment's intervertebral disc with a gray, inho-

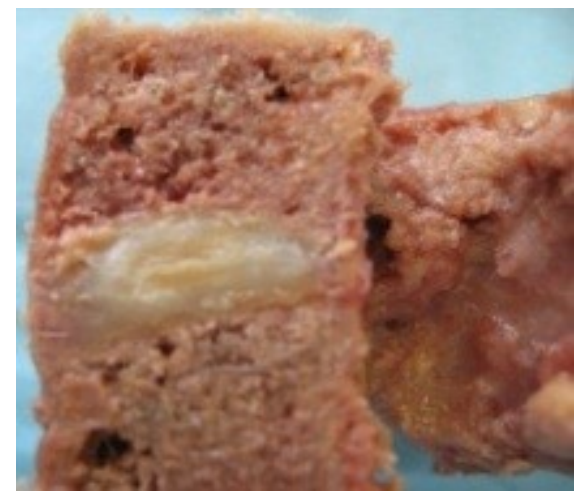

Fig. 5. Cervical Specimen in Axial Plane showing histological proporties of vertebra and intervertebral discs. mogeneous structure with unclear distinction between the nucleus and annulus. These were classified to have grade III degeneration.

Results of one specimen were discarded because the specimen was compromised by the fracture of the superior endplate during the test on the laminectomy configuration. On the intact configurations the relationships of the applied load to the vertical deformation and to the anterior bulge showed a change in slope at loads of $262 \mathrm{~N} \pm 66 \mathrm{~N}$. On the average values the portions distinguished by the change in slope are almost linear $\mathrm{R}^{2}=0.99$ (Figure 6).

In the in Intact Configuration the average elasticity EIVD was found to be $19.5 \mathrm{MPa} \pm 6.4 \mathrm{MPa}$ for the C3-C4 segments and 14.4 MPa $\pm 4.3 \mathrm{MPa}$ for C5-C6. The results from the study show that when an intact spinal segment containing a disc with grade III or greater degeneration is compressed with $550 \mathrm{~N}$ an average of $0.116 \mathrm{~mm} \pm 0.002 \mathrm{~mm}$ anterior bulge occurs along with $0.382 \mathrm{~mm} \pm 0.128 \mathrm{~mm}$ of vertical deformation or height change (Figure 7).

After the laminectomy was performed the same spinal segments showed an average anterior bulge of $0.102 \mathrm{~mm} \pm 0.020 \mathrm{~mm}$ (Figure 8), posterior bulge of $0.095 \mathrm{~mm} \pm 0.070 \mathrm{~mm}$, and a vertical deformation of

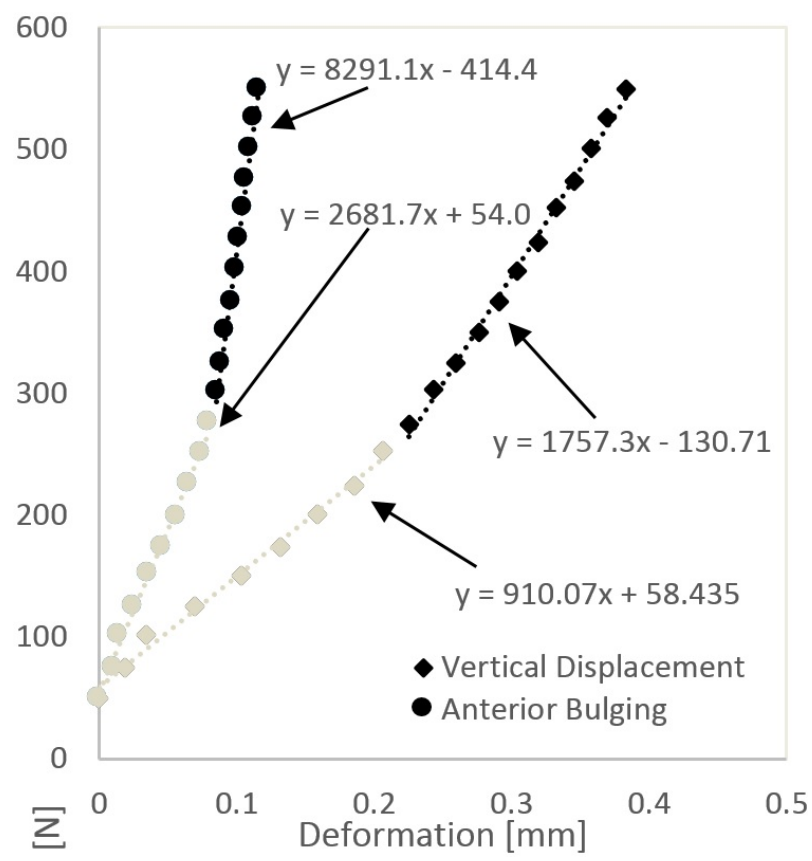

Fig. 6. Experimental results of the intact configuration: Average values of Anterior Bulge (mm) and Vertical Deformation (mm). 
$0.357 \mathrm{~mm} \pm 0.131 \mathrm{~mm}$ when compressed with $550 \mathrm{~N}$.

After a facetectomy was performed on the spinal segments an average anterior bulge of

$0.105 \mathrm{~mm} \pm 0.06 \mathrm{~mm}$, posterior bulge of

$0.051 \mathrm{~mm} \pm 0.025 \mathrm{~mm}$, and vertical deformation of

$0.356 \mathrm{~mm} \pm 0.105 \mathrm{~mm}$ were found (Figure 9).

As reported by Patwardhan ${ }^{17,18}$ a $250 \mathrm{~N}$ is a physiologic compressive load during activities involving minimal to moderate isometric muscle effort the disc has an average vertical deformation of

$0.205 \mathrm{~mm} \pm 0.060 \mathrm{~mm}$ with an anterior bulge of $0.074 \mathrm{~mm} \pm 0.014 \mathrm{~mm}$ that is reduced by

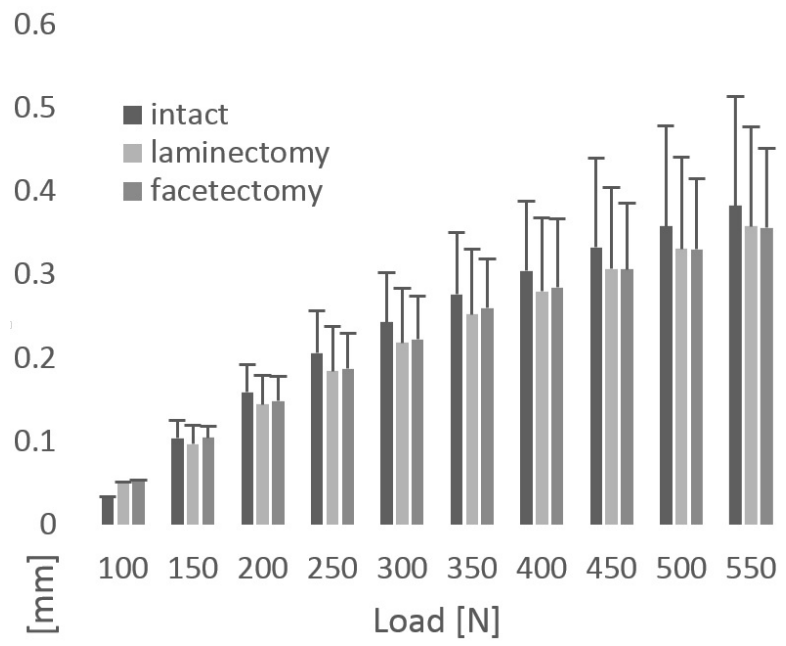

Fig. 7. Average values of vertical Deformation ( $\mathrm{mm}$ ) for the three configurations, Standard deviation is shown with error bars for the intact case.

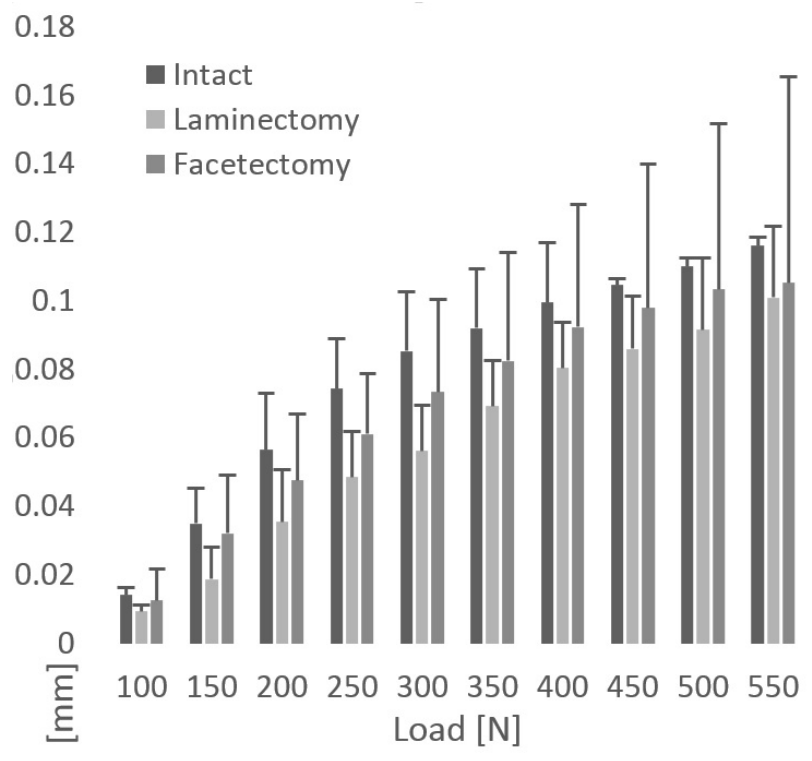

Fig. 8. Experimental results of the Anterior Bulge ( $\mathrm{mm}$ ) for the three: intact, laminectomy, and facetectomy.
$0.048 \mathrm{~mm} \pm 0.013 \mathrm{~mm}$ and $0.061 \mathrm{~mm} \pm 0.017 \mathrm{~mm}$ in the laminectomy and facetectomy respective configurations.

\section{Discussion}

The values of vertical displacements found in this study, despite the disc degeneration are comparable with values previously reported in literature (Figure $10)$.

Previous studies have investigated how laminectomy and facetectomy play a role in spinal stability and strength, many in the lumbar spine. ${ }^{19-22}$ This current study examined the effects of these procedures on the IVD in the cervical spine. The results show that performing a laminectomy reduced the anterior bulge of the spinal segments. However, after per-

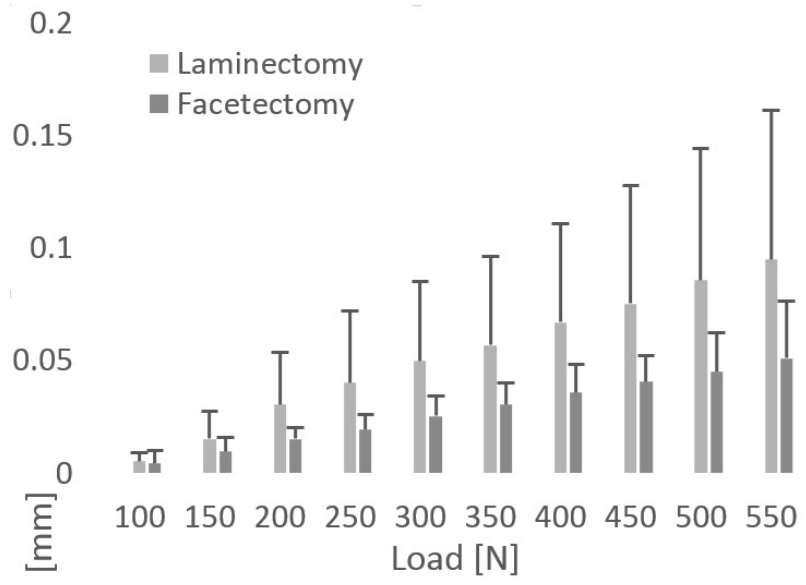

Fig. 9. Experimental results of the Posterior Bulge $(\mathrm{mm})$ for both the laminectomy and facetectomy with posterior access.

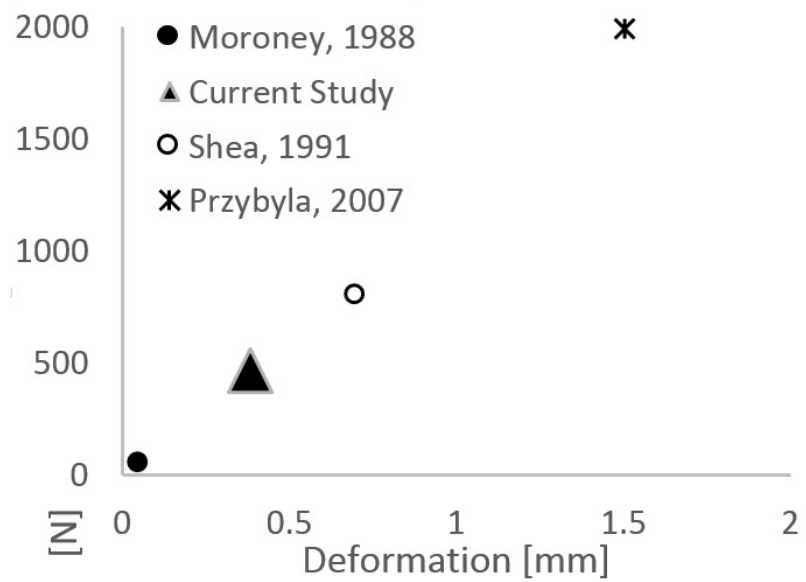

Fig. 10. Comparison of current data with previous reported studies of the Vertical Deformation ( $\mathrm{mm}$ ) 
forming the facetectomy the anterior bulge increased by $35.1 \%$ compared to the laminectomy (Figure 11a) but this difference was not significant $(\mathrm{F}=3.10)$. The posterior bulge decreased after facetectomy when compared to the laminectomy alone (Figure 11c). For a physiological load of $250 \mathrm{~N}$ the vertical displacement or spine segment height was reduced by $10.1 \%$ for an intact segment and 8.78\% for the laminectomy and facetectomy configurations with $\mathrm{F}=0.159$

$\left(F_{\text {crit }}=3.89\right)$ showing no statistical difference (Figure 11b).

In a previous study with lumbar spinal segments it was shown that laminectomy procedures increase stress on the annulus fibers. ${ }^{23}$ Previous studies also examined the role of a facetectomy procedure on the lumbar spine. ${ }^{23-25}$ It has been shown that facetectomy alters the loading pathway and increases stress on the IVD which leads to an increase in its degeneration. ${ }^{26}$ The removal of the weight bearing facet joint was shown in the lumbar spine to alter the stress on the annulus of the IVD. ${ }^{26}$ Our results show a significant $\left(\mathrm{F}=10.47, \mathrm{~F}_{\text {crit }}=5.12\right)$ decrease in vertical height for facetectomy followed by a decrease in posterior bulge compared to the posterior results post laminectomy (Figure 11c). These results suggest that there was a change in loading pattern between the laminectomy and facetectomy procedures that decrease posterior bulge and increased anterior bulge. The vertical deformation results show a $16.7 \%$ and $16.4 \%$ decrease after the laminectomy and facetectomy procedures, respectively (Figure 12b). At the maximal load of $550 \mathrm{~N}$ no statistical differences were found in all the variables considered (Figure 12).In this study it was ob-

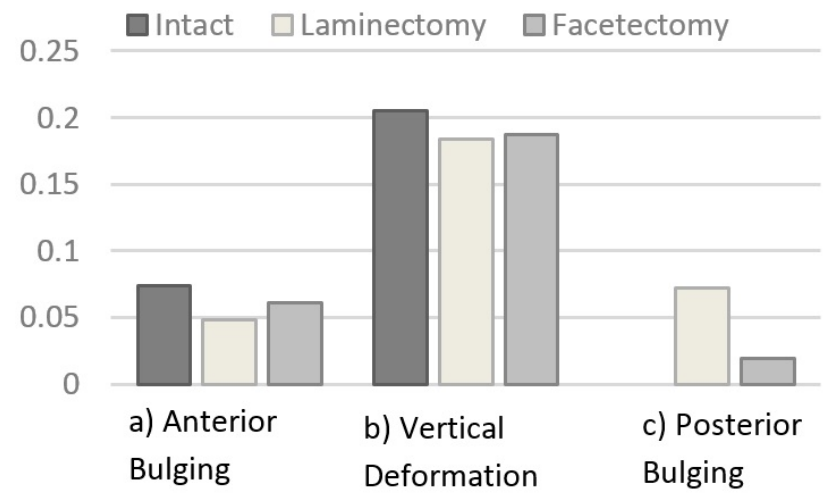

Fig. 11. Analysis of Average values for the different Spinal segment configuration at a common physiological Load of $250 \mathrm{~N}(\mathrm{~mm})$. served that the anterior bulge is limited to about 0.1 $\mathrm{mm}$ in the intact specimen for a certain loading range creating a plateau region while the axial (vertical) deformation increases; the bulge then continues to increase (Figure 6). A stiffening of the disc may be occurring. In the specimens post laminectomy there was a slight slope change around $450 \mathrm{~N}$ in the anterior bulge. No slope change was seen in the posterior bulge post laminectomy (Figure 9). After removal of the facet the IVD bulges in the anterior direction more than the posterior direction. The increase in anterior bulge after the facetectomy may be explained due to the thinner annulus in the posterior region. It was found in our study that facetectomy produced less posterior bulge then laminectomy under axial loads (Figure 11 and Figure 12). These results are found on spinal segments with at least grade III degeneration. Of the three variables considered we found statistical difference on the posterior bulge at $250 \mathrm{~N}$ but considering that the standard deviation of $0.007 \mathrm{~mm}$ was of the same order of the accuracy adopted, this difference should not be considered as significant.

In this study we found that the IVD in cervical spine segments with grade III or greater disc degeneration do not significantly alter their bulging pattern after laminectomy and facetectomy procedures. This may be due to the altered load distribution that occurs after these procedures. It was found that between laminectomy and facetectomy the anterior bulge increased and posterior bulge decrease. This study provides further insight into the load pattern and

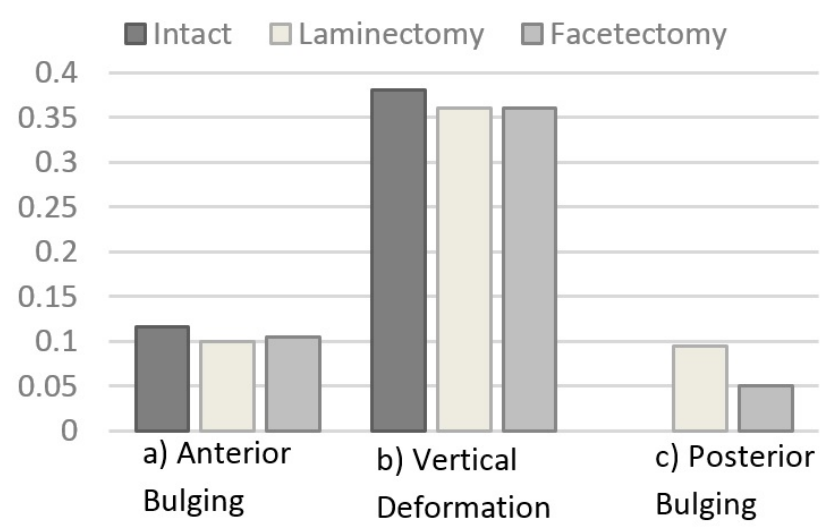

Fig. 12. Comparison of Bulging and vertical height deformation at maximal load of $550 \mathrm{~N}$. 
bulging of the degenerated disc and provides information for the spine surgical procedures and postoperative therapies to improve outcomes.

\section{References}

1. Hoy DG, Protani M, De R, Buchbinder R. The epidemiology of neck pain. Best Pract Res Clin Rheumatol. 2010 Dec;24(6):783-92.

2. Buckwalter JA. Aging and degeneration of the human intervertebral disc. Spine (Phila Pa 1976). 1995;20:1307-14.

3. Kra"mer J. Intervertebral Disk Diseases: Causes, Diagnosis, Treatment, and Prophylaxis. 3rd ed. Thieme Verlag; 2009.

4. Gerard CS, O'Toole JE. Current techniques in the management of cervical myelopathy and radiculopathy. Neurosurg Clin N Am. 2014

Apr;25(2):261-70.

5. Pfirrmann CW a., Metzdorf A, Zanetti M, Hodler J, Boos N. Magnetic Resonance Classification of Lumbar Intervertebral Disc Degeneration. Spine (Phila Pa 1976). 2001 Sep;26(17):1873-8.

6. Raynor RB, Pugh J, Shapiro I. Cervical facetectomy and its effect on spine strength. J Neurosurg. 1985 Aug;63(2):278-82.

7. Markolf KL, Morris JM. The structural components of the intervertebral disc. A study of their contributions to the ability of the disc to withstand compressive forces. J Bone Joint Surg Am.; 1974 Jun 1;56(4):675-87.

8. Shah JS, Hampson WG, Jayson MI. The distribution of surface strain in the cadaveric lumbar spine.

J Bone Jt Surgery, Br Vol. 1978 May 1;60-B (2 ):246-51.

9. Wenger KH, Schlegel JD. Annular bulge contours from an axial photogrammetric method. Clin Biomech. 1997 Oct;12(7-8):438-44.

10. Spera D, Genovese K, Voloshin a. Application of Stereo-Digital Image Correlation to Full-Field 3-D Deformation Measurement of Intervertebral Disc. Strain. 2011 Jun 8;47:e572-87.

11. Cuchanski M, Cook D, Jegapragasan M, Whiting DM, Cheng BC. Measurement of disc bulge of the intervertebral disc: an in vitro study using human cadaver lumbar spine segments. ArgoSpine News J. 2010 Sep 1;22(2):73-80.
12. Heuer F, Schmidt H, Wilke H-J. The relation between intervertebral disc bulging and annular fiber associated strains for simple and complex loading. J Biomech. 2008 Jan;41(5):1086-94.

13. Moroney S, Schultz A. Load-displacement properties of lower cervical spine motion segments. J Biomech. 1988;21(9):769-79.

14. Shea M, Edwards W, White A, Hayes W. Variations of stiffness and strength along the human cervical spine. J Biomech. 1991;24(2).

15. Przybyla AS, Skrzypiec D, Pollintine P, Dolan P, Adams $M$ a. Strength of the cervical spine in compression and bending. Spine (Phila Pa 1976). 2007 Jul 1;32(15):1612-20.

16. Stemper BD, Yoganandan N, Pintar F a, Maiman DJ, Meyer M a, DeRosia J, et al. Anatomical gender differences in cervical vertebrae of sizematched volunteers. Spine (Phila Pa 1976). 2008 Jan 15;33(2):E44-9.

17. Patwardhan AG, Havey RM, Carandang G, Simonds J, Voronov LI, Ghanayem AJ, et al. Effect of compressive follower preload on the flexion-extension response of the human lumbar spine. J Orthop Res. 2003 May;21(3):540-6.

18. Patwardhan AG, Havey RM, Ghanayem AJ, Diener H, Meade KP, Dunlap B, et al. Load-Carrying Capacity of the Human Cervical Spine in Compression Is Increased Under a Follower Load. Spine (Phila Pa 1976). 2000 Jun;25(12):1548-54.

19. Zander T, Rohlmann a, Klöckner C, Bergmann

$\mathrm{G}$. Influence of graded facetectomy and laminectomy on spinal biomechanics. Eur Spine J. 2003

Aug;12(4):427-34.

20. Bisschop A, Mullender MG, Kingma I, Jiya TU, van der Veen AJ, Roos JC, et al. The impact of bone mineral density and disc degeneration on shear strength and stiffness of the lumbar spine following laminectomy. Eur Spine J. 2012 Mar;21(3):530-6. 21. Bisschop A, van Royen BJ, Mullender MG, Paul CPL, Kingma I, Jiya TU, et al. Which factors prognosticate spinal instability following lumbar laminectomy? Eur Spine J. 2012 Dec;21(12):2640-8.

22. Tai C-L, Hsieh P-H, Chen W-P, Chen L-H, Chen W-J, Lai P-L. Biomechanical comparison of lumbar spine instability between laminectomy and bilateral laminotomy for spinal stenosis syndrome - an experimental study in porcine model. BMC Muscu- 
loskelet Disord. 2008 Jan;9:84.

23. Lee KK, Teo EC. Effects of laminectomy and facetectomy on the stability of the lumbar motion segment. Med Eng Phys. 2004 Apr;26(3):183-92. 24. Abumi K, Panjabi MM, Kramer KM, Duranceau J, Oxland T, Crisco JJ. Biomechanical Evaluation of Lumbar Spinal Stability After Graded Facetectomies. Spine (Phila Pa 1976). 1990;15(11).

25. Pintar FA, Cusick JF, Yoganandan N, Reinartz J, Mahesh M. The Biomechanics of Lumbar Facetectomy Under Compression-Flexion.. Spine. 1992. p. 804.

26. Haher TR, O'Brien M, Dryer JW, Nucci R, Zipnick R, Leone DJ. The Role of the Lumbar Facet Joints in Spinal Stability: Identification of Alternative Paths of Loading. Spine (Phila Pa 1976). 1994;19(23).

\section{Disclosures}

The authors declare no relevant disclosures.

\section{Corresponding Author}

Farid Amirouche, $\mathrm{PhD}$, Professor and Director of Orthopedics Research, Department of Orthopaedics, University of Illinois at Chicago, $835 \mathrm{~S}$. Wolcott Ave., Room E270, Chicago, IL 60612. amirouch@uic.edu

Published 2 May 2015.

This manuscript is generously published free of charge by ISASS, the International Society for the Advancement of Spine Surgery. Copyright @ 2015 ISASS. To see more or order reprints or permissions, see http://ijssurgery.com. 